\title{
Pengamanan Data dengan Kombinasi Teknik Kriptografi Rabin dan Teknik Steganografi Chaotic LSB
}

\author{
Jamaluddin'), Muhammad Zarlis ${ }^{2)}$ dan Tulus ${ }^{3)}$ \\ Program Studi D3 Manajemen Informatika Universitas Methodist Indonesial) \\ Jl. Hang Tuah No. 8 Medan 20152 Indonesia \\ Fakultas Ilmu Komputer dan Teknologi Informasi Universitas Sumatera Utara ${ }^{2)}$ \\ Jl. Universitas No. 24A Kampus USU Medan 20155 Indonesia \\ Fakultas MIPA Universitas Sumatera Utara ${ }^{3)}$ \\ Jl. Bioteknologi No. 1 Kampus USU Medan 20155 Indonesia \\ e-mail : james coleps@yahoo.com ${ }^{1)}$ m.zarlis@yahoo.com ${ }^{2)}$ tulus@usu.ac.id $^{3)}$
}

\begin{abstract}
Abstrak
Pengamanan data pada era komputerisasi sekarang ini multlak diperlukan dalam bidang jaringan komputer dan cloud computing. Penelitian ini menggunakan Algoritma Kriptografi Rabin yang dikombinasikan dengan teknik Steganografi Chaotic Least Significant Bits (CLSB) untuk melakukan pengamanan data pada sistem komunikasi data. Kunci yang digunakan pada algoritma Rabin menggunakan generator pembangkit bilangan acak dengan menggunakan Teorema Fermat didalam pengecekannya. Dalam penelitian perancangan dilakukan untuk dapat mengkombinasikan dua model sistem pengamanan data yakni Kriptografi dan Steganografi agar pengamanan data pada sistem komunikasi data lebih maksimal. Kekuatan dan kelemahan algoritma kriptografi dan teknik steganografi diukur berdasarkan kecepatan proses dan kerumitan dari algoritma untuk ditembus oleh pihak lain. Hasil pengujian yang didapatkan pada tesis ini adalah bahwa sistem kombinasi antara algoritma kriptografi Rabin dan teknik Steganografi Chaotic Least Significant Bits lebih baik dan lebih sulit untuk dideteksi jika dibandingkan dengan algoritma pembandingnya dan teknik steganografi sebelumnya.
\end{abstract}

Kata kunci : Kriptografi, Steganografi, Rabin, Chaotic Least Significant Bits, Teorema Fermat.

\section{Pendahuluan}

Perkembangan komputer saat sekarang ini sudah semakin cepat, salah satu tren yang sangat mengemuka belakangan ini adalah Cloud Computing (Komputasi Awan). Cloud Computing menawarkan cara baru untuk menyediakan jasa pada layanannya melalui media internet. Dengan teknologi Cloud Computing, unit komputer tidak lagi memerlukan suatu sistem operasi tertentu, tidak memerlukan media penyimpanan ataupun aplikasi tertentu pada komputernya karena semua hal tersebut sudah disediakan oleh penyedia layanan Cloud Computing $^{[7,11]}$.
Pada internet, telah disediakan banyak aplikasi yang berbasis Cloud Computing untuk berbagai macam pekerjaan. Contohnya aplikasi Google Docs disediakan sebagai aplikasi perkantoran yang berbasis Cloud Computing. Pada aplikasi Google Docs disediakan fasilitas-fasilitas seperti yang dimiliki oleh Microsoft Office pada Windows ataupun OpenOffice pada Linux. Aplikasi lain yang memanfaatkan layanan Cloud Computing adalah Google Translate, yakni aplikasi online yang memudahkan kita untuk menterjemahakan suatu kata atau kalimat dari satu bahasa ke bahasa lainnya.

Walaupun banyak kemudahan-kemudahan yang diberikan oleh layanan Cloud Computing, tetap saja ada beberapa kekurangan yang dimiliki oleh layanan ini. Salah satu kekurangan dari layanan Cloud Computing adalah segi keamanan. Pemanfaatan Cloud Computing memungkinkan pengguna untuk menyimpan data pribadinya pada server penyedia layanan. Dari sisi inilah pengguna layanan Cloud Computing tidak dapat menjamin apakah data yang disimpannya tersebut aman dari orang-orang yang tidak memiliki hak untuk mengaksesnya ${ }^{[7]}$.

Pada penelitian yang dilakukan oleh G. Jai Arul Jose dan C. Sajee dibabarkan bahwa penyedia layanan Cloud Computing mengunakan Advanced Encryption Standard (AES) berbasis kriptografi untuk keamanan data pengguna ${ }^{[3]}$. Haris Amrullah Lubis membabarkan kerentanan AES terhadap beberapa jenis serangan umum pada kriptosistem, dan mengajukan teknik One-Time Pad pada sistem Cloud Computing ${ }^{[5]}$.

Pada tulisan ini, penulis tertarik untuk menggunakan algoritma kriptografi Rabin untuk sistem pengaman data. Disamping itu, penulis tertarik untuk mengkombinasikan algoritma kriptografi Rabin dengan teknik Steganografi Chaotic Least Significant Bits (CLSB) sehingga keamanan data lebih terjaga.

\section{Kriptografi}

Kriptografi (Cryptography) berasal dari bahasa Yunani, terdiri dari dua suku kata yaitu kripto dan graphia. Kripto artinya menyembunyikan, 
sedangkan graphia artinya tulisan. Jadi, kriptografi adalah ilmu yang mempelajari teknik-teknik matematika yang berhubungan dengan aspek keamanan informasi, seperti kerahasiaan data, keabsahan data, integritas data, serta autentikasi data $^{[2]}$. Tetapi tidak semua aspek keamanan informasi dapat diselesaikan dengan kriptografi. Kriptorafi dapat pula diartikan sebagai ilmu atau seni untuk menjaga keamanan pesan. Ketika suatu pesan dikirim dari suatu tempat ke tempat lain, isi pesan tersebut. Untuk menjaga pesan, maka pesan tersebut dapat diubah menjadi suatu kode yang tidak dapat dimengerti oleh pihak lain.

Enkripsi adalah sebuah proses penyandian yang melakukan perubahan sebuah kode (pesan) dari yang bisa dimengerti (plaintext) menjadi sebuah kode yang tidak bisa dimengerti (ciphertext). Sedangkan proses kebalikannya untuk mengubah ciphertext menjadi plaintext disebut dekripsi. Proses enkripsi dan dekripsi memerlukan suatu mekanisme dan kunci tertentu ${ }^{[6,8,9,13,15]}$.

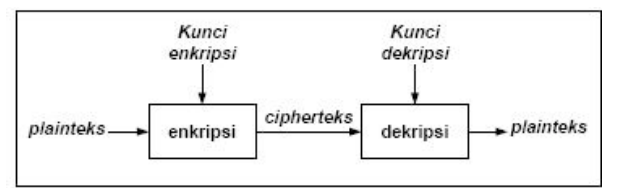

Gambar 1. Proses Enkripsi dan Dekripsi pada Kriptografi

Ada empat tujuan mendasar dari kriptografi yang juga merupakan aspek keamanan informasi yaitu $^{[6,8,9,13,15]}$ :

1. Privacy/Confidentiality: yaitu usaha menjaga informasi dari orang yang tidak berhak mengakses (mengaransi bahwa data pribadi tetap pribadi).

2. Integrity: yaitu usaha untuk menjaga data atau sistem tidak diubah oleh yang tidak berhak.

3. Authentication: yaitu usaha atau metoda untuk mengetahui keaslian dari informasi, misalnya apakah informasi yang dikirim dibuka oleh orang yang benar (asli) atau layanan dari server yang diberikan benar berasal dari server yang dimaksud.

4. Availability: berhubungan dengan ketersediaan sistem dan data (informasi) ketika dibutuhkan.

\subsection{Algoritma Rabin}

Algoritma Rabin pertama sekali diperkenalkan pada tahun 1979 oleh Michael O. Rabin. Algoritma Rabin merupakan salah satu sistem kriptografi asimetris yang kemampuan keamanan datanya dibuktikan secara matematika karena menggunakan metode pemfaktoran bilangan secara cepat. Algoritma Rabin menggunakan sistem kunci publik dan kunci pribadi. Kunci publik nantinya akan digunakan pada proses enkripsi dan dapat diketahui oleh semua pihak (tidak rahasia), sementara kunci pribadi digunakan oleh penerima pesan untuk proses dekripsi dan bersifat rahasia ${ }^{[13]}$.
Algoritma pembangkitan kuncinya adalah sebagai berikut:

1. Pilih dua buah bilangan prima besar sebarang yang saling berbeda ( $p$ dan $q$ ).

2. Hitung $n=p \cdot q$

$\mathrm{n}$ adalah kunci publik. Bilangan prima $\mathrm{p}$ dan $\mathrm{q}$ adalah kunci pribadi.

Untuk mengenkripsi pesan hanya dibutuhkan kunci publik n, sedangkan untuk dekripsi, dibutuhkan bilangan $\mathrm{p}$ dan q sebagai kunci pribadi.

Teknik Rabin merupakan algoritma kriptografi kunci publik, maka semua orang dapat melakukan enkripsi dengan satu kunci publik tertentu, namun proses dekripsi hanya dapat dilakukan dengan menggunakan kunci privat oleh orang yang bersangkutan.

Proses enkripsi pada teknik Rabin sangat sederhana. Proses enkripsi tersebut dapat dituliskan dengan rumus berikut:

$$
c=m^{2} \bmod n
$$

Proses enkripsi yang sederhana ini menyebabkan proses enkripsi teknik Rabin ini dapat dilakukan dengan waktu yang singkat karena tidak memiliki proses yang rumit. Kesederhanaan ini merupakan keuntungan yang dimiliki oleh teknik Rabin untuk menghadapi keterbatasan sumber daya yang ada pada media kriptografi.

Proses dekripsi pada teknik Rabin dilakukan dengan menggunakan sebuah rumus sederhana, namun membutuhkan teorema Chinese remainder. Teorema ini digunakan untuk mendapatkan plainteks yang benar. Namun yang menjadi poin penting dari teknik ini adalah teknik Rabin tidak menghasilkan jawaban plainteks tunggal. Jawaban yang dihasilkan pada teknik Rabin ini terdiri dari 4 kemungkinan jawaban, tidak menghasilkan satu jawaban yang pasti. Rumus yang digunakan untuk mendapatkan kemungkinan jawaban yang benar (pesan asli) adalah sebagai berikut:

$$
\begin{aligned}
& m_{1}=c^{(p+1) / 4} \bmod p \\
& m_{2}=\left(p-c^{(p+1) / 4}\right) \bmod p \\
& m_{3}=c^{(q+1) / 4} \bmod q \\
& m_{4}=\left(q-c^{(q+1) / 4}\right) \bmod q
\end{aligned}
$$

Teknik Rabin selalu menghasilkan empat kemungkinan hasil, yang diberikan semuanya kepada orang yang melakukan dekripsi terhadap pesan rahasia. Kemudian orang tersebut harus dapat menentukan mana pesan yang sebenarnya dari keempat hasil dekripsi tersebut. Walaupun menghasilkan empat pesan berbeda pada akhirnya, namun penerima pesan dapat memilih pesan yang benar dengan tidak terlalu sulit, karena pesan yang benar seharusnya akan terlihat jelas dibandingkan dengan ketiga hasil dekripsi yang lain.

\section{Steganografi}

Steganografi adalah sebuah seni dan ilmu untuk menyembunyikan sebuah pesan dengan cara yang 
sedemikian rupa sehingga tidak ada orang lain, selain dari penerima yang dituju yang mengetahui mengenai pesan tersebut ${ }^{[15]}$. Keunggulan steganografi dari kriptografi adalah kemampuannya untuk membuat suatu pesan rahasia menjadi tidak terlihat, atau tidak mengundang orang lain yang tidak mengetahui untuk peduli atau penasaran, lain halnya dengan kriptografi yang mengacak sebuah pesan tertulis menjadi suatu yang tidak berarti, yang dapat membuat orang lain menjadi penasaran dan ingin mengetahui arti dari pesan acak tersebut, hingga akhirnya melakukan percobaan untuk menerjemahkan pesan tersebut.

Steganografi biasanya terdiri dari dua sistem, yaitu sistem untuk menyembunyikan pesan dan sistem untuk mengambil pesan. Dalam sistem-sistem tersebut terkandung enam komponen penyusun, antara lain ${ }^{[15]}$ :

1. Pesan rahasia $(\mathrm{M})$

2. Cover Document $(\mathrm{C})$

3. Stego Document $(\mathrm{Z})$

4. Stego Key $(\mathrm{K})$

5. Fungsi penyembunyi $f(M, C, K) \rightarrow \mathrm{Z}$

6. Fungsi detektor $f^{\prime}(Z, C, K) \rightarrow M$

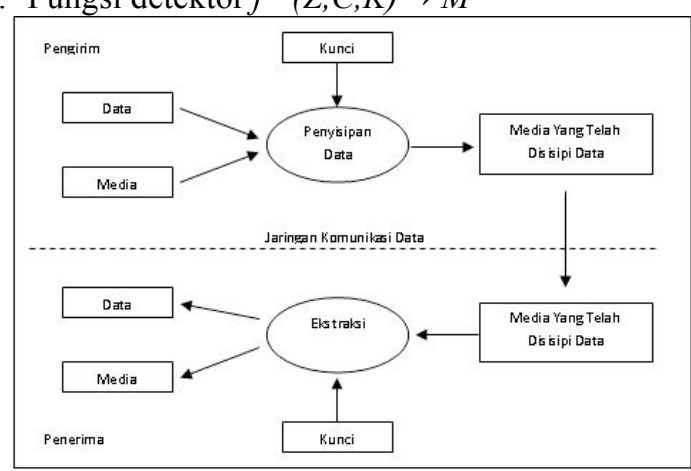

Gambar 2. Proses Penyisipan dan Ekstraksi pada Steganografi

\section{Analisis Sistem}

Diagram analisis permasalahan dari sistem yang akan dibuat berupa diagram konteks yang merupakan model untuk menunjukan bagaimana sistem berhubungan dengan data yang diinputkan dan output data yang didapati. Berikut ini merupakan diagram konteks dari sistem:

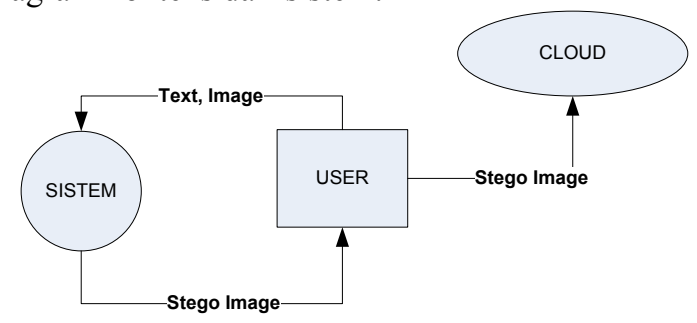

Gambar 3. Diagram Konteks Sistem

Aspek fungsional yang terdapat didalam sistem meliputi adanya fungsi pembangkitan kunci, fungsi enkripsi, fungsi dekripsi, funsi penyisipan pesan pada media dan fungsi ekstraksi pesan dari media yang digunakan.

\section{Perancangan Sistem Pengamanan Data}

Perancangan Sistem dimulai dari merancang sistem untuk proses enkripsi dan dekripsi, yaitu berupa prosedur dengan dasar pembuatannya mengacu pada algoritma Rabin. Pada proses enkripsi, input yang digunakan dalam penelitian ini merupakan bilangan numerik yang berupa nomor kartu kredit yang biasa digunakan untuk transaksi elektronik. Selanjutnya data hasil enkripsi akan disisipkan pada gambar yang disediakan oleh aplikasi dengan teknik Chaotic LSB.

Tahapan-tahapan dalam proses enkripsi dan dekripsi dilakukan dengan cara:

a. Proses pembangkitan kunci rahasia yaitu bilangan prima dilakukan secara acak oleh sistem pada aplikasi.

b. Mengetikkan inputan pesan yang akan di rahasiakan

c. Proses enkripsi dilakukan sehingga didapatkan nilai chipertext dari data aslinya.

d. Data chipertext yang akan disisipkan menggunakan teknik Chaotic LSB pada gambar yang sudah disediakan oleh aplikasi.

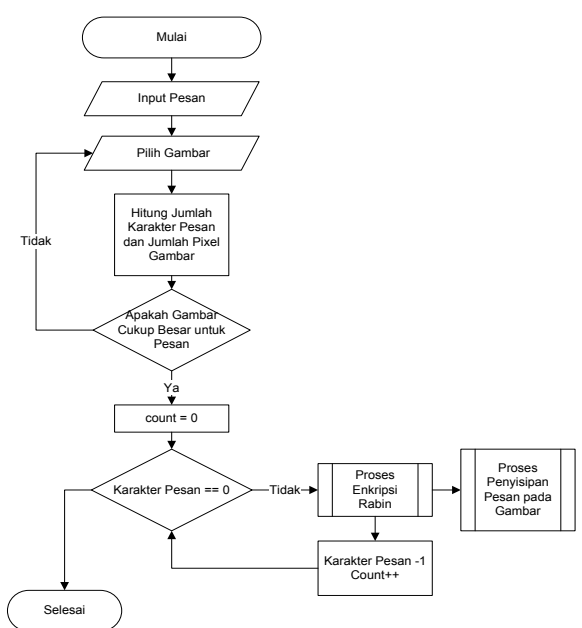

Gambar 4. Flowchart Proses Penyisipan Pesan pada Gambar

Kemudian data yang diterima oleh penerima akan dikeluarkan kembali dari gambar (stego-image) dan melalui proses dekripsi, data asli yang berupa nomor pada kartu kredit akan diterima. Dimana pesan ini (ciphertext) sudah dikembalikan lagi kebentuk semula, sehingga sudah dapat diproses.

\section{Implementasi dan Pengujian}

Pada penelitian ini penulis menggunakan pemrograman Java untuk membangun aplikasi pengamanan data dengan algoritma Kriptografi Rabin dan Steganografi Chaotic LSB. Adapun proses yang terjadi didalam Algoritma Rabin adalah melakukan proses pengujian nilai pesan terhadap kunci yang dibangkitkan secara acak dengan algoritma Fermat yang telah dibahas sebelumnya. Kemudian nilai yang diinputkan tersebut akan 
dikonversikan kedalam bilangan biner dan diduplikasi dengan nilai yang sama.

Contoh :

Nilai yang dijadikan sebagai plainnum adalah 12

a. Nilai 12 akan dikonversi kedalam bilangan biner menjadi 1100 dan nilai 1100 dijadikan kedalam tipe data String

b. Nilai 1100 kemudian digandakan sehingga didapatkan nilai string 11001100 yang kemudian nilai tersebut dikonversi kembali kedalam bilangan decimal sehingga didapat nilai baru plainnum adalah 204

c. Nilai 204 inilah yang kemudian dienkripsikan menggunakan algoritma Rabin dengan rumus berikut: $c=m^{2} \bmod n$

d. Dengan rumus tersebut makan kita akan mendapatkan sebuah nilai yang dijadikan sebagai Ciphernum. Nilai Ciphernum ini akan selalu berubah-ubah dikarenakan nilai $n$ yang dihasilakan oleh algoritma fermat untuk kedua kunci bilangan prima juga akan selalu berbeda.

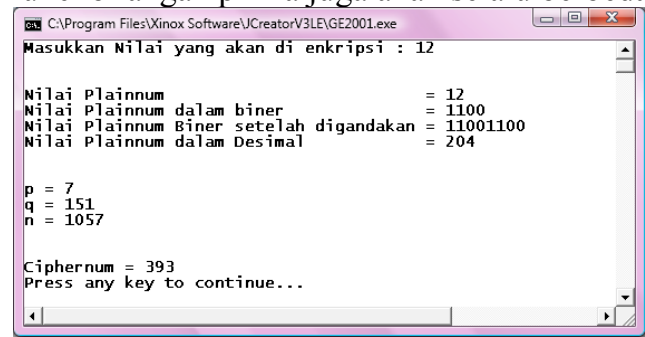

Gambar 5. Tampilan proses Enkripsi Rabin

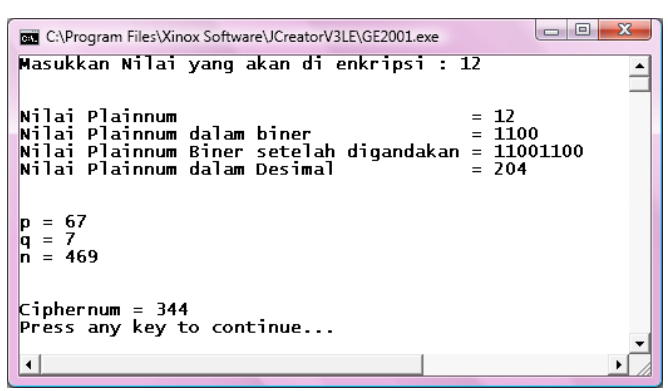

Gambar 6. Tampilan proses Ekripsi Rabin

Dari contoh proses enkripsi pada gambar 4.1 dan gambar 4.2 dapat dilihat bahwa nilai Ciphernum dapat berbeda nilainya dikarenakan kunci yang digunakan pada algoritma Rabin pada aplikasi ini menggunakan algoritma Fermat sehingga nilai $p$ dan $q$ dapat berbeda setiap aplikasi ini dijalankan.

Setelah didapatkan nilai Ciphernum maka langkah selanjutnya adalah proses melakukan proses penyisipan nilai Ciphernum tersebut pada cover stego yang berupa gambar dengan menggunakan metode Chaotic LSB. Proses penyisipan dilakukan adalah dengan cara menganti nilai pixel pada bits belakang dari gambar yang dijadikan sebagai media dengan nilai Ciphernum sampai seluruh bits pada Ciphernum telah disisipkan kedalam media stego yang digunakan. Pemilihan besarnya pixel dari gambar yang digunakan tergantung dari besar kecilnya data yang ingin disisipkan. Semakin banyak data yang ingin disisipkan maka semakin besar pula ukuran pixel dari gambar yang digunakan sebagai media stegonya.

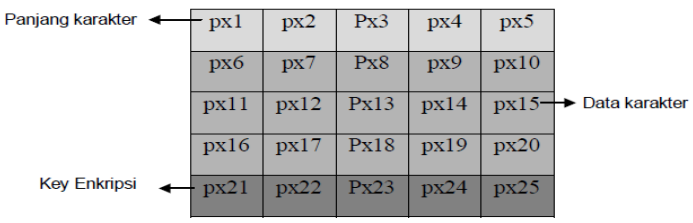

Gambar 7. Ilustrasi pixel pada gambar

Aplikasi pengamanan data dengan kombinasi algoritma kriptografi Rabin dan teknik Steganografi Chaotic LSB ini memiliki 2 tahapan proses yakni Proses Encoding yakni proses enkripsi dan penyisipan data pada media gambar (media stego) dan Proses Decoding yakni proses ekstraksi data yang ada didalam media gambar (media stego) untuk selanjutnya dilakukan dekripsi sehingga didapatkan pesan asli yang disisipkan didalam media gambar tersebut. Bentuk menu utama aplikasi ini dapat dilihat pada gambar 8 berikut:

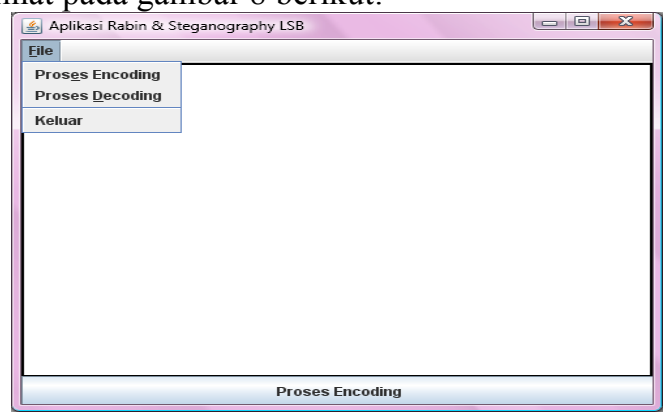

Gambar 8. Tampilan awal Alikasi Rabin \& Stego LSB

Saat kita memilih menu Proses Encoding maka kita akan diminta untuk mengetikan pesan pada layar tampilan setelah itu kita diminta untuk memilih gambar pada directory kita yang digunakan sebagai media stego. Pada penelitian kali ini gambar yang digunakan dibatasi hanya yang berektensi .PNG. Input pesan asli yang akan disisipkan kedalam gambar dapat dilihat pada gambar 9

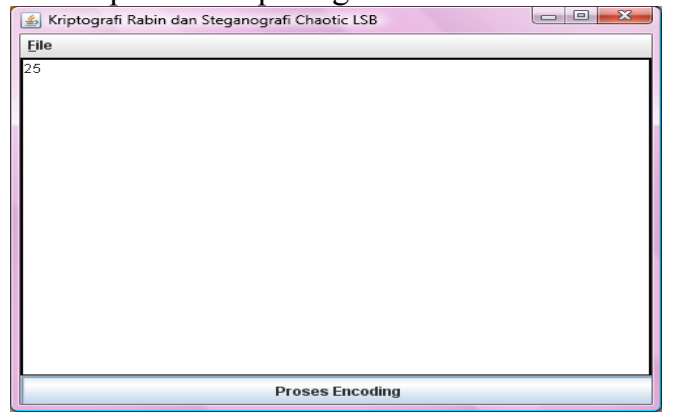

Gambar 9. Proses Input Pesan yang akan Disisipkan

Pada proses ekstraksi, prosesnya adalah kebalikan dari proses penyisipan. Hal yang dilakukan pertama adalah memilih gambar yang ingin dilakukan ekstrasi, pastikan bahwa didalam gambar tersebut memang terdapat data Ciphernum yang sudah disisipkan sebelumnya. Gambar yang sudah dideteksi terdapat stegoteksnya atau data tersembunyinya maka aplikasi akan mengambil header gambar dan memisahkannya dari body 
gambar. Hal ini dilakukan untuk menyaring data agar mendapatkan bit-bit hasil yang sudah disisipkan sebelumnya.

Langkah yang sama dapat dilakukan untuk proses Decoding dengan memilih menu Proses Decoding, setelah itu kita diminta untuk memilih gambar yang ingin dilakukan proses ekstraksi, selanjutnya tinggal mengklik tombol Proses Decoding

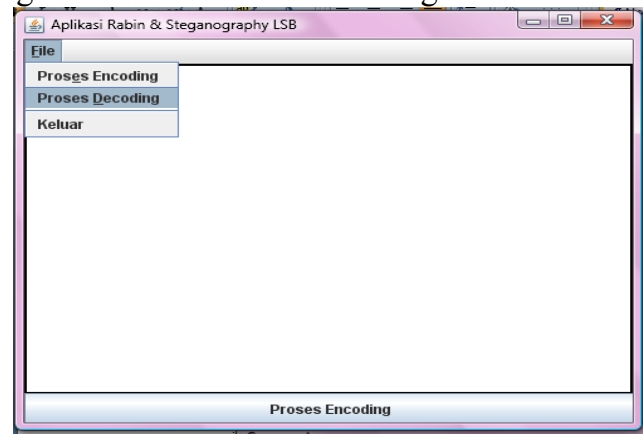

Gambar 10. Pemilihan menu proses decoding

Setelah memilih gambar yang akan diekstraksi maka akan muncul gambar stego, ingat pastikan bahwa gambar yang dipilih mengandung pesan rahasia didalamnya. Lalu klik tombol proses decoding seperti pada gambar 11. berikut:

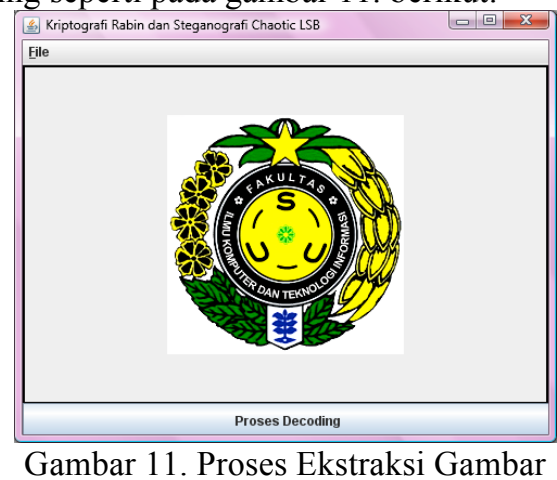

Data Chipernum yang didapatkan dari proses ekstraksi kemudian dilakukan proses dekripsi lagi untuk mengembalikan Chipernum menjadi Plainnum (data asli yang dapat dibaca). Pada proses dekripsi ini akan didapatkan 4 buah nilai. Dengan adalanya 4 nilai ini, aplikasi akan memilih nilai yang tepat yang merupakan data asli yang dienkripsi sebelumnya dengan menggunakan algoritma kriptografi Rabin. Disinilah fungsi dari duplikasi data yang dilakukan pada proses ekripsi berguna untuk menentukan salah satu data yang paling tepat yang merupakan data asli.

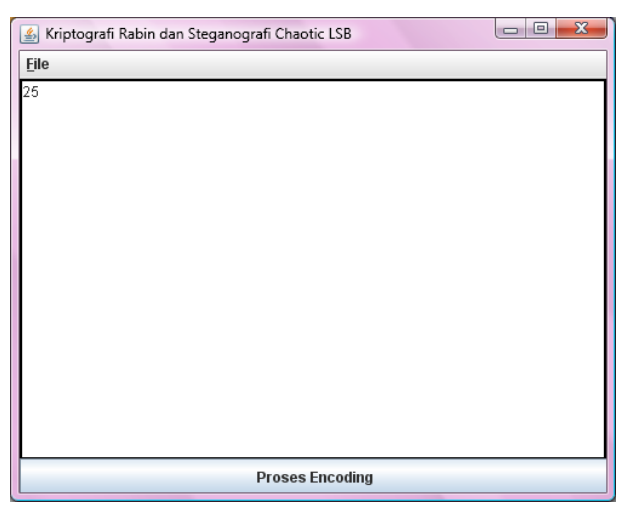

Gambar 12. Pesan rahasia hasil ekstraksi gambar stego

\section{Pembahasan}

Dari hasil pengujian terhadap rancangan yang sudah dibuat, terdapat beberapa kelebihan yang penulis dapatkan pada aplikasi pengamanan data dengan menggunakan kombinasi algoritma Rabin dan teknik steganografi Chaotic LSB, terutama dari citra (stego image) yang dihasilkan dari aplikasi ini.

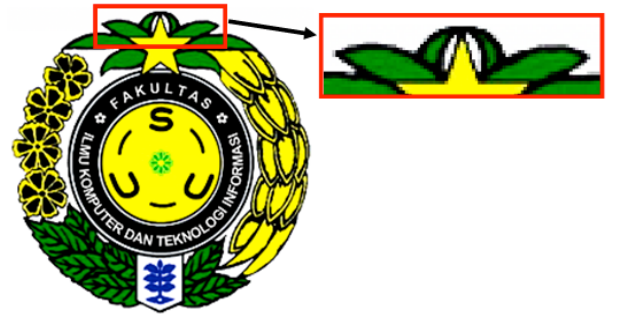

Gambar 13. Gambar asli sebelum disisipin pesan

Berikut ini penulis tampilkan perbandingan antara stego image yang menggunakan teknik steganografi LSB biasa dengan aplikasi yang menggunakan kombinasi algoritma Rabin dan teknik Steganografi Chaotic LSB.

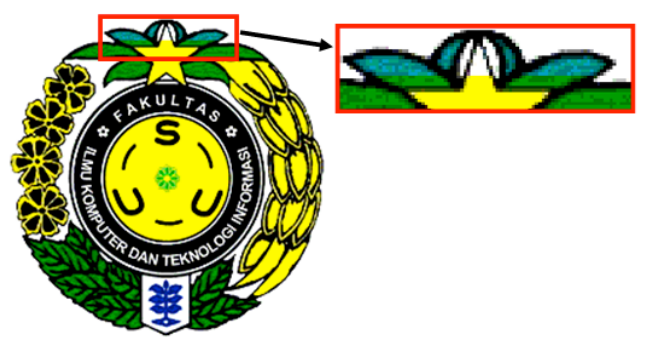

Gambar 14. Hasil Stego Image dengan Aplikasi Steganografi LSB

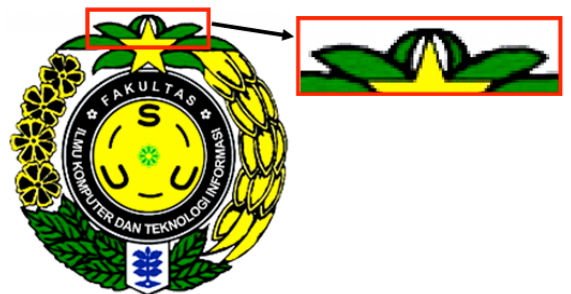

Gambar 15. Hasil Stego Image dengan Aplikasi Kombinasi Algoritma Rabin dan Teknik Steganografi Chaotic LSB

Dari hasil gambar diatas, apabila diperhatikan secara teliti akan terlihat jelas bahwa stego image yang dihasilkan dari aplikasi steganografi LSB memiliki kontras warna antara pixel yang disisipin dengan pesan rahasia dengan pixel yang tidak mengandung pesan rahasia didalamnya. Hal berbeda terlihat dari stego image yang dihasilkan dari aplikasi steganografi Chaotic LSB dimana stego image yang dihasilkan tidak terlihat secara jelas kontras warna antara pixel yang mengandung pesan rahasia dengan pixel yang tidak mengandung pesan rahasia, hal ini dikarenakan pemilihan pixel pada aplikasi steganografi Chaotic LSB dilakukan secara 
acak sehingga posisi pixel yang mengandung pesan rahasia tidak saling berdekatan.

Setelah membandingkan kontras warna yang dihasilkan dari aplikasi pengamanan data dengan kombinasi algoritma kriptografi Rabin dan teknik steganografi Chaotic LSB, penulis juga membandingan hasil ukuran file yang diperoleh dari 2 buah teknik steganografi yang berbeda yakni persentase ukuran file dari aplikasi steganografi LSB dan ukuran file dari aplikasi kombinasi yang dirancang oleh penulis. Berikut ini persentasi dari ukuran file terhadap ukuran file awal sebelum disisipin oleh pesan (ukuran file pesan $1 \mathrm{~KB}$ ):

Tabel 1. Persentase ukuran file gambar setelah disisipi pesan

\begin{tabular}{|c|c|c|}
\hline Ukuran File Asal & Ukuran File Hasil LSB & $\begin{array}{c}\text { Ukuran File Hasil } \\
\text { Aplikasi Kombinasi }\end{array}$ \\
\hline$<$ 10KB & $100 \%$ & $80 \%-85 \%$ \\
\hline 10KB s/d 50KB & $100 \%$ & $75 \%-80 \%$ \\
\hline $50 \mathrm{~KB}$ s/d 100KB & $100 \%$ & $75 \%-80 \%$ \\
\hline $100 \mathrm{~KB}$ s/d 1MB & $100 \%$ & $80 \%-85 \%$ \\
\hline $1 \mathrm{MB}$ s/d 10MB & $100 \%$ & $90 \%-100 \%$ \\
\hline
\end{tabular}

Dari tabel 1. terlihat bahwa pada aplikasi pengamanan data yang dirancang oleh penulis dengan mengunakan kombinasi algoritma Rabin dan teknik steganografi Chaotic LSB, terlihat bahwa untuk menyisipkan pesan dengan ukuran $1 \mathrm{~KB}$, ukuran media (gambar) yang sesuai dan yang paling efektif adalah yang berukuran 10 sampai 100 kali ukuran file yang ingin disisipkan.

\section{Penutup}

Dari implementasi dan pengujian yang telah dibahas sebelumnya, penulis dapat menyimpulkan beberapa hal mengenai penelitian ini, diantaranya:

1. Penggunaan algoritma kriptografi Rabin sangat baik untuk data numeric yang relative kecil tetapi tidak cukup efektif untuk data dengan ukuran yang besar.

2. Teknik steganografi Chaotic LSB dapat dikombinasikan dengan algoritma kriptografi dan hal ini menjamin data yang tersimpan pada media stego (citra) lebih aman dan mengurangi kecurigaan terhadap kerahasiaan data.

3. Media stego (gambar) yang dihasilkan dengan menggunakan teknik Chaotic LSB tidak mengalami perubahan warna yang kontras jika dibandingkan dengan citra yang dihasilkan oleh teknik steganografi LSB biasa.

4. Media stego (gambar) yang efektif berukuran 10 sampai 100 kali ukuran pesan yang ingin disisipin.

\section{Daftar Pustaka}

[1] Amigo, J.M., Kocarev, L., and Szczepanski, J., 2007. Theory and Practice of Chaotic Cryptography in Physics Letters A 366. Elsevier.

[2] Buchmann, J.A. 2004. Introduction to Cryptography. $2^{\text {nd }}$ ed. New York. Springer.

[3] Jose, G.J.A., and Sajeev, C. 2011. Implementation of Data Security in Cloud Computing in International Journal pf $P 2 P$ Network Trend and Technology July to Aug 2011.

[4] Kipper, G. 2004. Investigator's Guide to Steganography. Washington D.C. Auerbach Publications A CRC Press Company.

[5] Lubis, H.A. Studi Analisis Aplikasi Algoritma One-Time Pad dan AES pada Keamanan Sistem Cloud Computing.

[6] Mollin, R.A. 2007. An Introduction to Cryptography. $2^{\text {nd }}$ ed. New York. Chapman \& Hall / CRC.

[7] Rittinghouse, J.W and Ransome, J.F., 2010. Cloud Computing: Implementation, Management, and Security. Florida. CRC Press, Taylor and Francis Group.

[8] Schmeh, K. 2003. Cryptography and Public Key Infrastructure on the Internet. West Sussex, John Wiley \& Sons Ltd.

[9] Schneier, B. 1996. Applied Cryptography: Protocols, Algorthms, and Source Code in C. John Wiley \& Sons, Inc.

[10] Sehgal, N.K., Sohoni, S., Xiong, Y., Fritz, D., Mulia, W., Acken, J.M. 2011. A Cross Section of the Issues and Research Activities to Both Information Security and Cloud Computing In IETE Technical Review 2011. Vol 28.

[11] Sullivan, D. 2010. The Definitive Guide to Cloud Computing. Realtime Publishers.

[12] Soplanit, S., Sunarsa, C., dan Naga, D.S. 2005. Pengamanan Data dengan Chaotic Least Significant Bit Encoding (CLSBE) dan NewChaotic Substitution Image Encryption (NCSIE) pada Seminar Nasional SIIT 2005, Universitas Kristen Petra, Surabaya, 28 Juli 2005.

[13] Stalling, W. 2005. Cryptography and Network Security Principles and Practices, $4^{\text {th }}$ edition, Prentice Hall.

[14] Stinson,D.R., 1995, Cryptography Theory and Practise, CRC Press, Inc., Florida.

[15] Wayner, P. 2009. Disappearing Cryptography, - Information Hiding: Steganography \& Watermaking. $3^{\text {rd }}$ ed. Burlington. Elsevier Inc. 